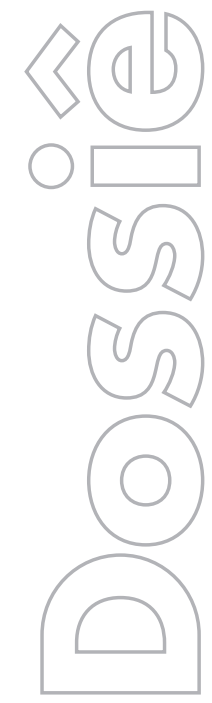

revista

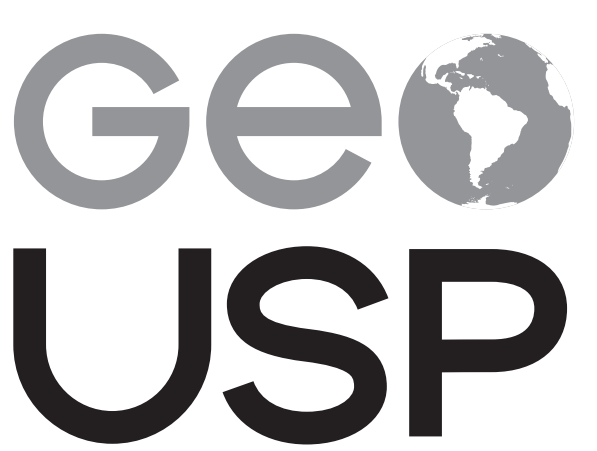

espaço e tempo

Volume $22 \cdot n^{\circ} 3$ (2018)

\section{A trajetória teórico-intelectual de uma geografia urbana crítica e radical}

\section{César Simoni Santos USP \\ Isabel Pinto Alvarez \\ USP \\ p. $515-528$}

Como citar este artigo:

SANTOS, C. S.; ALVAREZ, I. P. A trajetória teórico-intelectual de uma geografia urbana crítica e radical. Geousp Espaço e Tempo (Online), v. 22, n. 3, p. 515-528, dez. 2018. ISSN 2179-0892.

Disponível em: <https://www.revistas.usp.br/geousp/article/view/152974>. doi: http://dx.doi.org/10.11606/issn.21790892.geousp.2018.152974.

\section{(c) $(1) \circledast$}

Este artigo está licenciado sob a Creative Commons Attribution 4.0 License. 


\title{
A trajetória teórico-intelectual de uma geografia urbana crítica e radical
}

\section{Resumo}

Este artigo situa a trajetória da geografia urbana crítica uspiana como parte do movimento de renovação da Geografia brasileira que se inicia já na década de 1970. A ideia central procura reforçar o fato de que essa trajetória é marcada por um processo de ruptura teórico-metodológica realizado a partir de uma leitura acurada das obras de Karl Marx e Henri Lefebvre. Contudo, o corte epistemológico apresenta essa ruptura em relação tanto à própria história da geografia quanto a suas demais vertentes críticas, internas e externas. $\bigcirc$ rigor das reflexões e pesquisas, o trabalho de estudo e formação e o compromisso com a produção de um conhecimento crítico tornam essa perspectiva de análise uma importante referência para a explicação do mundo, desnudando a radicalidade das contradições sociais. Tendo em vista o escopo do artigo, identificam-se dois momentos dessa trajetória: o primeiro, entre o fim dos anos 1970 e o começo dos 80, quando se abre a ruptura metodológica; o segundo, a partir dos anos 90 , quando a leitura rigorosa e intensa dos trabalhos de Lefebvre aprofunda os horizontes da crítica.

Palavras-chave: Geografia urbana crítica e radical. Espaço mercadoria. Estado. Produção do espaço urbano. Corrente marxista-lefebvriana.

\section{The theoretical-intellectual trajectory of a critical and radical urban geography}

\begin{abstract}
This article sets out the path of critical urban geography in Brazil as part of the Brazilian Geography renewal movement, which began in the 1970s. The central idea seeks to reinforce the fact that this trajectory is marked by a process of theoretical and methodological rupture. An accurate reading of the works of Karl Marx and Henri Lefebvre supported this rupture. However, the epistemological cut that brings this rupture also impose distinctive marks to this renewed urban geography detaching it from the other so-called critical perspectives (internal and external to this disciplinary field). The rigor of research, study and training, and the compromises with the production of critical knowledge make this perspective an
\end{abstract}


important reference to show the radicality of social contradictions. In the scope of the article, two moments of this trajectory are identified: firstly, between the late 1970s and the early 1980s, when the methodological rupture starts; and, secondly, in the 1990s, when the rigorous and intensive reading of Lefebvre's works deepens the horizons of criticism.

Keywords: Critical and radical urban geography. Space-commodity. State. Production of urban space. Marxist-Lefebvrian perspective.

\section{Introdução}

A historicidade da ciência consiste na historicidade dos métodos de que se utiliza e na do exame e compreensão do próprio pensamento.

Álvaro Vieira Pinto, 1979

Tomando por base os termos em epígrafe, é importante considerar que não se trata de apresentar uma história da geografia urbana crítica produzida pelos professores do Departamento de Geografia da USP (DG-USP), uma vez que a extensão, diversidade e qualidade dessa produção dificultaria uma análise acurada no espaço de um artigo. Por outro lado e principalmente, pensa-se que o fundamental seja explicitar algumas das principais contribuições no campo teórico metodológico que distinguem essa produção, tendo em vista que se podem considerar que essas marcam uma ruptura no campo da geografia urbana e que, igualmente, vêm orientando a reflexão de inúmeras pesquisas e estudos nas últimas décadas, sobretudo no próprio DG-USP, mas também fora dele.

Esse movimento no campo da geografia urbana, marcado, de início pela insatisfação de muitos geógrafos com o nível de comprometimento social e político do conhecimento geográfico produzido até então, especialmente no contexto da ditadura militar instalada em 1964, situa-se no âmbito do que Silva (1984), Verdi (2015), Andrade (1977), ente outros, classificam como movimento de renovação da geografia brasileira. Segundo Silva (1984), esse movimento de renovação emergiu numa velha instituição, o DG, ainda que contestasse a geografia oficial. Mas Verdi $(2015,2016)$ considera que os termos dessa reviravolta devem ser compreendidos também diante de um movimento de envergadura comparável revelado pela trajetória da própria Faculdade de Filosofia, Letras e Ciências Humanas (FFLCH) que, com a produção de pesquisas e profundas reflexões teóricas sobre a realidade nacional, construiu uma tradição do pensamento crítico brasileiro a partir de um posicionamento comprometido com as classes mais oprimidas. Segundo Verdi (2015, p. 53), "a FFLCH foi um dos berços do renascimento do movimento estudantil na ditadura (Moraes, 2004), ' e é justamente esse movimento estudantil que vai radicalizar também a própria ciência geográfica com um outro entendimento da realidade".

1 MORAES, A. C. R. Memorial para concurso de Professor Titular. Faculdade de Filosofia, Letras e Ciências Humanas, Universidade de São Paulo, 2004. 
Carlos (2002) mostra que a década de 1960 foi um marco divisório na geografia brasileira, com uma parte dos geógrafos, especialmente aqueles ligados ao IBGE, no Rio de Janeiro, aproximando-se das análises quantitativas, sob a influência de Bryan Berry. Mas, em São Paulo, de longa tradição de diálogo com a geografia francesa, outros rumos foram tomados. Conforme a autora (2002, p. 164):

Contrapondo-se às idéias esposadas por Berry e fiéis à escola francesa de interpretação da realidade, desenvolvem-se as pesquisas baseadas nos fundamentos da chamada Geografia Ativa, sob a influência de Pierre George - que nasce da constatação da extrema mobilidade das situações atuais, conduzindo a um estudo ativo que pode inspirar ou guiar as ações e, que a meu ver, prepara o caminho das grandes transformações do final dos anos 70 na Geografia brasileira.

No texto apresentado no 30 Congresso Brasileiro de Geógrafos (considerado um marco no movimento de renovação da geografia brasileira), ${ }^{2}$ Gonçalves (1978) entende esse momento de intensos debates como momento de crise. Ele questiona a cientificidade da disciplina situando o desenvolvimento das ciências, e da geografia em particular, na sua relação com o desenvolvimento do modo de produção capitalista e com o domínio do Estado. Traçando sua análise a partir de uma periodização dos caminhos da ciência geográfica, Gonçalves (1978) aponta, de um lado, a geografia de tradição historicista, cujas análises eram constituídas num raciocínio linear, sem levantar contradições ou rupturas e, de outro, a produção geográfica pautada no positivismo lógico, que, ao construir análises a partir de modelos que buscam coesão, se alinha ao pragmatismo acrítico solidário com a ordem do imperialismo estadunidense. Ambas as visões seriam ideologicamente vinculadas aos interesses das classes dominantes. Imbuído desse espírito, Gonçalves (1978) advoga a necessidade de uma ruptura teórica que repense o objeto da geografia: o espaço como produção da sociedade, dentro da formação econômico social capitalista.

Moreira (2000) assinala que o movimento de renovação da geografia brasileira desdobrou-se em torno da renovação do conceito de espaço, tornado objeto da geografia, a partir de um conjunto de obras, entre as quais destaca A Geografia: isso serve, em primeiro lugar, para fazer a guerra, de Yves Lacoste, Marxismo e geografia, de Massimo Quaini, e Por uma geografia nova, de Milton Santos.

Explorando a ideia de que o movimento de renovação da geografia antecede os eventos de 1978 e analisando especificamente a produção acadêmica (teses e dissertações) do DG no período de 1964 a 1985, Verdi (2015) observa que os temas de pesquisa, bem como as abordagens, revelam a preocupação com o compromisso social dos trabalhos. Além disso, para a autora, o movimento de renovação da geografia brasileira deve ser compreendido a partir da clivagem metodológica que se estabelece em relação à geografia positivista e historicista herdada da tradição da Escola Francesa de Geografia. $O$ contexto político do país (o período da ditadura) e a aproximação de alguns geógrafos do materialismo histórico e da dialética seriam as bases da abertura desse novo caminho de interpretação da realidade pela ciência geográfica.

2 Segundo Moreira (2000), o 30 Congresso, de junho de 1978, marcou um momento de convergência de ideias e reflexões que já vinham ocorrendo nos anos anteriores mas de forma difusa e, portanto, sem caráter hegemônico. 
Sem nenhuma pretensão de tratar do movimento de renovação da geografia brasileira como um todo, os parágrafos acima querem apenas mostrar que a geografia urbana crítica que emergiu no DG-USP, ainda que não possa ser compreendida apenas a partir da mobilização geral no campo disciplinar maior, não se desvincula dela. Além disso, somando-se ao horizonte de expectativas desenhado naquele instante, ela faz coro com a descontinuidade crucial que resulta no chamado movimento de renovação crítica: trata-se efetivamente de um dos troncos da ruptura teórica e metodológica empreendida no e pelo pensamento geográfico brasileiro.

Assim, longe de esgotar os temas e as abordagens da geografia urbana crítica nestes 40 anos, o presente texto busca recobrir dois momentos que compõem esse processo de ruptura. primeiro, no final dos anos 1970 e começo dos 80, quando teses e artigos publicados por professores do DG-USP abriram um novo caminho teórico metodológico para a análise do urbano, foi marcado fundamentalmente pela assimilação do materialismo dialético e da obra de Marx. À luz dessas movimentações no campo epistêmico, demonstrando sólido conhecimento da geografia produzida até aquele momento, essa produção parte da crítica simultânea ao realizado (no campo disciplinar) e à realidade, construindo outra possibilidade de análise e compreensão do espaço geográfico. Assim, os conceitos de produção, trabalho, propriedade, apropriação, divisão social do trabalho e alienação, tornam-se chave para a redefinição das noções de paisagem, espaço, região, cidade e urbano.

O segundo momento, já nos anos 1990, nos coloca diante da radicalidade desta produção, tendo por base a maior aproximação com os estudos organizados em torno da obra de Henri Lefebvre. Como será demonstrado, essa aproximação possibilitou a pavimentação dos caminhos de análise que iriam dar corpo a um ramo dos estudos urbanos dentro da geografia crítica. É desse ramo que a consolidação de um pensamento crítico sobre o papel do Estado na produção do espaço e das políticas públicas como solução para a crise urbana ganha lugar de destaque em meio à crítica à economia política do espaço, aprofundando a radicalidade dos posicionamentos emergentes.

\section{Abrindo os caminhos da ruptura epistêmica}

Para refletir sobre esse primeiro momento, procuramos ler alguns trabalhos produzidos entre 1978 e 1984, portanto, compreendendo o período entre o $3 \circ$ e o 4 Encontro Nacional de Geógrafos da AGB, lócus de profundos debates e socialização de pesquisas e reflexões teóricas. Nesse período, entre aqueles que situaram suas pesquisas no campo da geografia urbana crítica e que mantinham vínculos institucionais (como docente ou pós-graduando, num primeiro momento) com o DG-USP, podemos citar Amélia Luisa Damiani, Ana Fani Alessandri Carlos, Odette Carvalho de Lima Seabra, Lea Francesconi, Margarida Maria de Andrade, Sandra Lencioni e Amália Ines Geraiges de Lemos. ${ }^{3}$ Com produções mais vinculadas à teoria e ao método, mas que dialogaram (não necessariamente de modo convergente) com o campo da geografia urbana crítica, situamos Armando Correa da Silva e Milton Santos (que à época

3 Em 1979, defenderam sua dissertação de mestrado Ana Fani Alessandri Carlos e Odette de Carvalho Lima SEABRA; em 1980, Margarida Maria de Andrade; em 1985. Amélia Luisa Damiani e Sandra Lencioni. Margarida Maria de Andrade, entrou como docente no Departamento em 1973, Odette de Carvalho Lima Seabra, em 1979, Ana Fani

Alessandri Carlos e Sandra Lencioni, em 1982, e Amélia Luisa Damiani, em 1988. 
não era vinculado ao DG). Importa considerar que na formação desses que se tornaram docentes do DG-USP, dois mestres foram fundamentais: o Prof. Pasquale Petroni e a Profa Lea Goldenstein.

No período assinalado, conforme Silva (1984), Carlos (2002), Verdi (2015), o Boletim Paulista de Geografia, editado pela AGB foi um canal de publicações essencial para a divulgação dos debates que se realizavam naquele momento.

Por isso, procurando assinalar, nesse momento, os fundamentos de uma produção acadêmica que permitiu a leitura crítica da cidade e do urbano a partir do materialismo dialético, propondo uma clara ruptura metodológica, apontando a construção de um diálogo profícuo entre a geografia urbana e a economia política, selecionamos as dissertações de Ana Fani Alessandri Carlos e Odette Carvalho Lima Seabra, ambas de 1979, bem como os artigos publicados por Ana Fani Alessandri Carlos e Sandra Lencioni, estando um deles no periódico $O$ Borrador 4 e o outro nos Anais do 4o congresso Brasileiro de Geógrafos, evento ocorrido no ano de 1984. Também aqui, longe de querer esgotar o tema ou abordá-lo em toda sua extensão, a escolha teve por objetivo mostrar como, nestes anos, encontram-se os elementos primordiais que se desdobram no longo caminho da geografia urbana crítica produzida no DG-USP.

Um componente presente em todas essas referências, ora de maneira mais explícita, ora subentendido, é a afirmação da cidade como produto social e histórico. Se ela hoje parece banal ou superficial, é preciso dizer que, à época, conceber o espaço e a cidade nessa perspectiva foi o traço basilar de toda a arquitetura teórico conceitual que se desenvolvia. Uma questão de método se impôs ao se questionar a tradição da geografia de descrever as paisagens. Desta maneira emergiu a problematização da relação entre espaço e paisagem, tomando-se a paisagem como o aspecto visível, a aparência, o ponto de partida das observações e descrições e a manifestação fenomênica de uma essência ligada às relações sociais contraditórias, num claro diálogo com as ideias presentes na Dialética do concreto, de Karel Kosik.

Na dissertação de Carlos (1979), observa-se a profunda preocupação com a construção de uma teoria sobre o espaço geográfico. Com uma perspectiva oposta à elaboração de modelos e fórmulas, a categoria trabalho foi mobilizada para se entenderem as relações sociais e as da sociedade com a natureza. Segundo Carlos (1979, p. 28, grifo do original), "o espaço geográfico deve ser concebido como produto das relações que se estabelecem entre a sociedade e o meio circundante. Tais relações de produção, ocorrem através do processo de trabalho". A autora colocava em xeque a visão no espaço e da cidade como externas à sociedade ou como mero palco ou suporte das ações humanas. $\bigcirc$ espaço e a cidade foram entendidos como produto das relações de produção determinadas em cada momento histórico. Carlos (1979, p. 49) afirma ainda que a cidade capitalista "está submetida às leis da acumulação capitalista, daí a estreita relação entre este e o processo de urbanização". Desse modo, a autora assinala que o capital é a categoria determinante, capaz de dominar e organizar o espaço. Faz isso a partir da observação metrópole, que é a expressão máxima da relação entre a concentração desse capital e a urbanização. A concentração das forças produtivas no espaço urbano viabiliza a diminuição do tempo de rotação do capital, e o Estado tem papel crucial nesse processo, porque direciona os investimentos em favor do processo de acumulação. Há, portanto, nessa dissertação, um claro diálogo com a economia política, com a filosofia, com a sociologia e com a história.

4 Publicação coordenada por estudantes e editada pela AGB. 
Um desdobramento rico desta concepção encontra-se na compreensão do espaço como mercadoria. Um caminho para a apreensão das formas que esse desdobramento assumiu pode ser encontrado na dissertação de Seabra (1979) e no artigo de Carlos e Lencioni (1982).

Seabra (1979), num trabalho claramente situado no campo de debates da geografia urbana, partiu da observação de uma sazonalidade na densidade ocupacional de Santos, das transformações no comércio, bem como das novas formas edificadas junto à orla, e questionou os conteúdos desse processo. Acompanhando o movimento das indústrias de construção, concebendo seus produtos como mercadoria, observou que o movimento de transformação da orla de Santos dizia respeito ao movimento do capital, que auferia lucros extraordinários decorrentes da captura da renda de monopólio. Assim, a autora mostra que as determinações do processo não eram apenas de ordem local, e que não seria possível compreendê-lo sem considerar os elementos de reprodução da sociedade brasileira naquele momento, fosse no plano nacional (com o crescimento econômico e a desigualdade social), fosse no da concentração que se expressava na metrópole de São Paulo e passava a impor novas práticas no âmbito da reprodução da vida urbana, definindo, por exemplo, a produção da segunda residência na orla de Santos como parte da "indústria dos lazeres", numa reflexão que sinalizava a necessidade de compreender a totalidade do processo de reprodução social.

Carlos e Lencioni (1982) entendem o espaço geográfico e o próprio homem como resultado do processo civilizatório, cuja centralidade está no trabalho. Nesse sentido, ainda que reconheçam a dimensão natural do espaço, questionam sua finitude, uma vez que os limites de ocupação do espaço seriam dados pelo grau de desenvolvimento das forças produtivas.

Ao analisar o espaço como mercadoria, as autoras buscam entender os termos da valorização do espaço. Conforme Carlos e Lencioni (1982, p. 7):

O valor do espaço é dado pela posição que cada parcela do espaço ocupa dentro do espaço global, cuja totalidade é determinada pela formação econômica social capitalista. [...] Assim, o fato de uma parcela espacial não conter trabalho objetivado, não exclui seu valor na medida em que essa parcela entra e influi no processo geral de produção de valores como potencialidade, acabando por influenciar, ou mesmo atuar nesse processo.

Trata-se de uma formulação que coloca a centralidade da análise no processo de valorização e não nas rendas fundiárias, normalmente associadas aos modos de distribuição do valor. As autoras apontam a especificidade da mercadoria espaço a partir de sua aparição como meio de produção; assim, se ele é, de um lado, "originalmente premissa do processo de produção, por outro lado, é resultado, formando uma unidade indissociável" (Carlos; Lencioni, 1982, p. 6). Inicialmente considerado produto, o espaço ganha aqui também a dimensão de ser meio do processo de produção; a produção de um novo espaço envolve o consumo de espaços já produzidos. Aqui está uma possível gênese da formulação que compreende o espaço como produto, meio e condição da reprodução do capital e da sociedade, que foi desenvolvida por Carlos (1987, 2011) posteriormente e é amplamente veiculada em estudos urbanos de perspectiva crítica. Essa formulação, a nosso ver, é importante porque aponta a superação da noção de "organização do espaço" (oriunda da Geografia Ativa francesa) pela de "produção do espaço" (já 
numa perspectiva marxista-lefebvriana, que eleva os termos da análise da cidade, conduzindo à compreensão de que a cidade não é apenas o lugar que concentra os negócios e o capital; ela é produzida também como parte do capital e se insere no movimento e circulação do capital).

Por outro lado, ela é, simultânea e contraditoriamente, o lugar de reprodução da vida, das práticas sociais, das relações mais pessoais, o que necessariamente conduz às lutas pelo espaço. Conforme Carlos e Lencioni (1982, p. 8):

modo pelo qual se efetiva a apropriação é determinado pelas condições específicas e históricas de uma dada sociedade. Isso quer dizer, por exemplo, que numa comunidade tribal a apropriação é coletiva, enquanto na sociedade capitalista é privada. Portanto, o processo de produção e consumo capitalista do espaço é mediado pela propriedade privada.

Cabe observar que, embora não tenham, naquele momento, explorado essa formulação, ela é fundamental para entender toda a discussão posterior que as próprias autoras desenvolverão sobre a segregação espacial e sobre os processos de fragmentação e hierarquização do espaço urbano, abrindo-se um amplo leque de pesquisas e reflexões nessa direção. A propriedade privada da terra se torna, na trajetória da geografia urbana crítica, uma categoria central de análise, sendo a mediação que permite entender o processo de segregação socioespacial como constitutivo da produção do espaço urbano, uma vez que ela é mobilizada em função dos processos de acumulação (via valorização e/ou ganhos rentistas), colocando em questão as possibilidades de uso e de apropriação do espaço. Portanto, ela é essencial para explicar o lugar que cada grupo social ocupa na cidade e na metrópole, tornando-se ao mesmo tempo um conteúdo para a compreensão das lutas pelo espaço. A centralidade da propriedade privada do espaço na explicação das dinâmicas sociais urbanas define também o centro a partir do qual a crítica ao Estado e à burocracia e a análise do cotidiano se vinculam aos termos da crítica à economia política.

\section{A radicalidade da crítica lefebvriana na geografia urbana}

Uma das expressões mais evidentes e atuais da radicalidade da crítica da geografia urbana desenvolvida no DG-USP é, sem dúvida, o não alinhamento às soluções arranjadas no âmbito das políticas públicas. Isso abre caminho para a produção de um conhecimento que não fica refém do Estado, de suas formas ou das disputas em torno dele; abre-se, assim, em consonância com os fundamentos da crítica que observa o cotidiano, a possibilidade de reconhecer que o debate, e tampouco a vida, não se pode encerrar nessa esfera, nessas dimensões.

Compartilhada por uma ampla parcela dos professores e pesquisadores do Laboratório de Geografia Urbana da USP (Labur), essa posição pode ser admitida como um ponto de unidade; um posicionamento comum compartilhado mesmo entre os grupos e as perspectivas que se ramificaram à medida que se aprofundava o trabalho acadêmico. Pode-se arriscar a hipótese de que, muito provavelmente, esse posicionamento tem origem no modo pelo qual se apreendeu a leitura do trabalho de Marx, como já foi sugerido, tendo em vista que outros grupos de influência marxista se posicionaram muito diferentemente. Contudo, além disso, e o que parece ter sido o passo decisivo ou, ao menos, um dos importantes momentos de autocertificação desse posicionamento crucial, foi a consolidação, nos anos 1990, de um ambiente de trabalho 
e estudo em torno do engajamento na leitura da produção de Henri Lefebvre e na perspectiva de elaboração de uma geografia urbana de feições muito particulares, mas fundamentalmente crítica e radical.

Pelo exposto, não se pode dizer que esse tenha sido o momento de início de um projeto de renovação crítica que conduziria a Geografia Urbana brasileira, ou parte dela, a suas novas feições. Aliás as bases dessa renovação já estavam dadas em proporções diversas entre geógrafos estrangeiros e brasileiros, como procuramos pontuar acima. Contudo, como numa espécie de entroncamento, esse foi o momento de reunião dos esforços que resultariam no desenvolvimento de uma nova linhagem na história do pensamento geográfico brasileiro. Foi a consolidação do trabalho realizado por esta geração que, além de ter aberto uma senda no horizonte teórico e de trabalho para a pesquisa em geografia urbana, formou muitos pesquisadores diretamente no esforço de orientação e nos grupos de estudos do Labur. Desse modo, agregam-se elementos importantes para que já se possa falar numa "escola de geografia urbana marxista-lefebvriana da USP” (Carlos, 2002; Damiani, 2012; Pinto, R., 2018).

Os anos 1990 aparecem aqui como o momento de consolidação de uma orientação mais ou menos autoconsciente do trabalho que se realizava no âmbito da Geografia Urbana do DG- USP. Foi o primeiro momento após o término do importante grupo de leitura dos trabalhos de Henri Lefebvre sob a supervisão de José de Souza Martins. Esse grupo se formara para ler textos de Karl Marx, fazendo parte do que ficou conhecido como a segunda geração dos seminários de leitura de Marx na FFLCH-USP. Foram 13 anos de estudo da obra e do método de Marx, a partir de 1975. Os estudos sobre o filósofo francês só terão início em 1988 e durarão cinco anos, encerrando-se o grupo em 1992. Participaram desse grupo cinco professoras do DG-USP, entre elas, Amélia Luísa Damiani, Ana Fani Alessandri Carlos e Odette Seabra.

Após esse período de 18 anos, tem início a fase que será ao mesmo tempo de amadurecimento da experiência anterior, de consolidação de uma orientação teórica compartilhada e da abertura de novas frentes de investigação. Tudo isso sendo operado na condução de pesquisas, nos cursos de graduação e pós-graduação (muitas vezes oferecidos com a presença simultânea das três professoras mencionadas) nas atividades de orientação e nos grupos de estudos que se multiplicaram no DG nesse momento (sobretudo aqueles alocados no Labur). $\bigcirc$ percurso de formação desse ambiente acadêmico e intelectual da Geografia Urbana brasileira está parcialmente documentado no primeiro volume da revista lefebvriana francesa La Somme et le Reste (Damiani et al., 2002). Assim, a perspectiva da chamada Geografia Urbana Lefebvriana começava a assumir uma posição de destaque no debate da Geografia Urbana feita no DG-USP, enquanto Lefebvre tornava-se um autor e uma influência incontornável na formação dos alunos.

É preciso deixar claro também que nem a entrada de Marx nem a de Lefebvre no pensamento geográfico da USP se devem apenas à influência do chamado Grupo do Martins. $\bigcirc$ grupo do Labur já vinha de uma tradição crítica que tinha um pé no movimento de renovação da geografia e o outro na aproximação das ideias e teorias do pensamento marxista, este último influenciado tanto pelo engajamento político quanto pela herança que haviam deixando as gerações precedentes (Verdi, 2016). Mesmo Martins recebera influência direta da geração de professores que havia inaugurado o trabalho de leitura sistemática das obras de Karl Marx 
também na FFLCH. Ele tinha sido aluno de Fernando Henrique Cardoso, Octavio lanni, Ruth Cardoso e Fernando Novais: todos membros do conhecido grupo de leitura de $O$ capital, que aconteceu entre 1958 e 1959.

Contudo, apesar do minucioso e extenso conhecimento dos textos do filósofo alemão por parte de geógrafos como Pasquale Petrone e Lea Goldenstein, eles não haviam sido incorporados ao trabalho acadêmico da geografia no Brasil, declaradamente e com o rigor metodológico adequado, antes do período de 13 anos que começa em 1975 e marca a duração do seminário de leitura coordenado por Martins. Desse modo, assim como não se pode considerar o trabalho desse grupo o responsável pela entrada do método de Marx no trabalho acadêmico da geografia brasileira, não se pode igualmente desprezar sua influência, o mesmo valendo para a incorporação da leitura de Henri Lefebvre. No que diz respeito ao desenvolvimento da temática urbana, é a partir da influência desse grupo que a década de 1990, no ambiente intelectual do DG-USP, será marcada, de um lado, pela consolidação da trajetória acadêmica e conceitual do pensamento de Milton Santos e, de outro, por um intenso debate estruturado em torno das categorias do pensamento lefebvriano.

Mas, se havia uma forma de apropriação da leitura de Marx que ajudou a definir os caminhos dessa vertente dos estudos urbanos, seguramente havia também uma orientação muito precisa para a leitura dos trabalhos de Henri Lefebvre. Isso ajudou a sustentar um projeto de geografia urbana crítica e radical que criticou as soluções que situavam o planejamento, as políticas públicas e o Estado em geral como o caminho e a possibilidade efetiva de transformação social. Essa geografia urbana fez uma crítica radical ao Estado.

Observando muito amplamente, nota-se a presença persistente de pelo menos três eixos teórico-conceituais que ajudaram a orientar a forma de apreensão dos trabalhos do filósofo francês. A produção do espaço, o mais difundido e mais arraigado entre eles, possibilitou simultaneamente o trabalho com as categorias da crítica à economia política no cerne da investigação geográfica e a observação das contradições sociais para além dos termos deixados pelo pensamento marxista. Assim, ao mesmo tempo, o espaço reforçava sua presença no âmbito do pensamento social crítico e, com isso, novas dimensões eram incorporadas no universo de trabalho do geógrafo. A estrapolação das contradições do modo de produção capitalista para além dos muros da fábrica, uma imagem apresentada por Lefebvre (1999) e amplamente adotada pela vertente lefebvriana, permitiu observar os tensionamentos entre o uso e a troca no que diz respeito ao espaço urbano. Esse segundo eixo teórico-conceitual não pode prescindir de dimensões prosaicas negligenciadas pela filosofia moderna tais como o corpo e o cotidiano, diretamente ligados e atingidos pelas forças políticas e econômicas que recorrem, se instalam, tomam, se apropriam, produzem e reproduzem o espaço social, constituindo uma trama de contradições conflitos e embates. Assim, o choque entre sistemas normativos, concepções sociais e programas com as demais dimensões da vida sugere a observação das contradições entre os conteúdos sociais e as abstrações decorrentes tanto do modo como funciona a economia quanto do modo como opera o Estado. A posição contra a abstração que ultrapassa os limites do debate epistemológico e da cognição, o terceiro eixo teórico-conceitual inspirado pela herança do marxismo, é um dos saltos do pensamento lefebvriano que será igualmente importante no desenvolvimento de uma crítica que ultrapassa o âmbito das contradições da mercadoria e do processo de acumulação para se dirigir contra o planejamento, as normas, a tecnocracia, em suma, o Estado. 
Ainda muito sumariamente, esses grandes eixos teórico-conceituais deram sentido e foram bastante trabalhados em algumas linhas de investigação. Três delas, que se definem a partir de três críticas, também se tornaram importantes na consolidação dos trabalhos dessa vertente: a crítica ao cotidiano, à economia política do espaço e ao planejamento (derivada da crítica dirigida à racionalidade e à tecnocracia). Ao lidar com a dimensão espacial e, portanto, simultaneamente, com o confronto entre as contradições que vêm da história e as forças de ordenamento social (leis, planejamento e formalismos), essa perspectiva se depara com uma dialética que deve dar conta das contradições do espaço, tema de natureza simultaneamente crítico-analítica e metodológica, que canalizou boa parte do esforço teórico empreendido pelo grupo organizado em torno de três geógrafas.

Ainda nos anos 1990, a confluência temática daí resultante dá origem a alguns artigos e debates que ganham maior visibilidade e sinalizam os rumos de uma geografia urbana crítica e radical que se consolidava. A temática do uso ganha lugar de destaque a partir do capítulo escrito por Odette Seabra (1996) no livro organizado por José de Souza Martins, até hoje um de seus trabalhos mais lidos. Algumas consequências dessa reflexão podem ser capturadas NE seus trabalhos futuros, sobretudo em profunda correlação com a temática que observa a desagregação da vida de bairro em sua livre-docência (Seabra, 2003) e no artigo publicado na revista Cidades (Seabra, 2004), entre outros.

No livro O espaço no fim de século: a nova raridade, Amélia L. Damiani (1999a, 1999b) deixa apontados dois caminhos de investigação que serão objeto de desenvolvimento futuro e reaparecerão em seus trabalhos após a virada do século. A observação das contradições do espaço a partir das relações entre a "lógica [formal]" e a "[lógica] dialética" (Damiani, 1999a) se desdobra em suas considerações sobre o esvaziamento primevo que se opera numa sorte de acumulação primitiva do espaço no artigo publicado no primeiro número da Revista Cidades (Damiani, 2004a), importante revista na história da geografia urbana brasileira. Suas considerações sobre A cidade e a crise (Damiani, 1999b), no mesmo livro de 1999, lança igualmente as bases de outra preocupação que estaria presente nos trabalhos futuros de Damiani (2004b, 2009).

Ana Fani Alessandri Carlos reúne em sua tese de livre-docência (Carlos, 2000) duas dimensões de igual importância em seus trabalhos dos anos 1990. Após a formulação, em sua tese de doutorado, da tríade segundo a qual o espaço deve ser apreendido pela reflexão teórica como condição, meio e produto da atividade social (Carlos, 1987), duas dimensões amparadas nessa formulação, estruturalmente interpenetradas e articuladas em seu trabalho, passam a tomar corpo, como fica claro em seu trabalho de livre-docência (Carlos, 2000). Uma delas se relaciona mais diretamente com as formas da experiência que atravessam as dinâmicas espaciais contemporâneas e que incluem a identificação do habitante com os espaços de referência para a vida e trazem os vínculos concretos e afetivos que perpassam o cotidiano e constituem os elementos da memória. Essa dimensão da análise foi observada diante do fenômeno da mundialidade do espaço, o que remete aos vínculos desse universo da experiência cotidiana, normalmente identificados na escala local, aos processos mais gerais que incidem nas formas de vida tais como a normatização do espaço, o consumo ordenado, a homogeneização dos hábitos e a difusão das imagens ligadas aos estilos de vida de uma sociedade marcada pela programação do mercado. Antes da livre-docência, esse mesmo conjunto já havia sido articulado no livro O lugar no/do mundo, de 1996 (Carlos, 1996). 
Apesar da profunda relação entre a perspectiva lefebvriana e os temas debatidos e que se tornaram objeto de pesquisa e reflexão pelo grupo, um dos mais emblemáticos temas e conceitos associados ao pensamento de Henri Lefebvre não esteve muito presente nas produções ligadas a essa linhagem da Geografia Urbana do DG-USP, ao menos não direta ou declaradamente. $\bigcirc$ Direito à Cidade, nominalmente, como conceito ou parâmetro de organização do pensamento sobre o urbano, aparece pouco no início dos trabalhos do grupo. Logo, não foi em torno da noção do direito à cidade que a leitura lefebvriana do Labur se estruturou.

Esse aspecto é de grande importância se se mantém a expectativa de capturar elementos formativos ligados às particularidades da trajetória intelectual e teórica dessa geografia urbana crítica e radical. A grande circulação do trabalho de Henri Lefebvre atualmente se deve em grande medida à ampla difusão e aceitação do emblemático e potente rótulo que se tornou a noção do direito à cidade. Sem restrições para ser bem-vindo no alargamento das possibilidades, das condições e do volume do debate crítico, esse aspecto implica também a necessidade de algumas observações.

Frequentemente, na voz dos movimentos sociais e de algumas vertentes acadêmicas e de inserção direta no debate político nas mais distintas instâncias da burocracia estatal, o direito à cidade passa a ser reivindicado como pauta das políticas públicas. Dividido e disputado entre grupos, muitos deles de muito boa vontade, para lembrar os termos empregados por Lefebvre (1991) em O direito à cidade, a emblemática noção começa a figurar também e com relativa frequência, como dispositivo de legitimação de projetos de lei e de políticas públicas que muitas vezes mal conseguem romper com o cunho propagandista e demagógico de tais projetos, chegando poucas vezes ao nível de um assistencialismo empresariado. Na melhor das hipóteses, o emprego emblemático da noção de direito à cidade tem estado a serviço da reafirmação do Estado e de uma racionalidade ligada à boa gestão da tecnoestrutura. De tal sorte, projetos de planejamento urbano foram negociados em várias cidades no Brasil sob o rótulo da filiação lefebvriana, de modo que o direito à cidade passou a aparecer em planos diretores e, mesmo sem expressar uma ideia clara, o artigo segundo do Estatuto das Cidades recorre à noção do direito a cidades sustentáveis. Nesse campo, o direito à cidade acabou ficando mais próximo do pragmatismo e das políticas públicas do que da crítica radical ao Estado e ao planejamento.

grupo que percorria o caminho da crítica, que não podia deixar de ser também crítica ao Estado e ao planejamento, não disputou energicamente os sentidos implicados no emprego do termo, marcando só muito recentemente uma posição explícita e enfática diante do tema. ${ }^{5}$ Contudo, o sentido radical presente na utopia do direito à cidade não esteve fora do debate dessa geografia radical. A crítica à abstração e à alienação espacial, a aposta na apropriação social do espaço e o reconhecimento e valorização da dimensão do uso e do corpo constituem os elementos e a forma da presença da utopia do direito à cidade nas reflexões do grupo, sem que se aprofundasse, assim, o seu demasiado desgaste. A abordagem crítica, amparada nessas vias, não permite a conivência com as formas abstratas da dominação burocrática ou da submissão

5 Ao menos dois momentos capturam essa intenção: primeiro, o seminário Justiça Espacial e o Direito à Cidade, realizado em dezembro de 2015, o qual resultou num livro com o mesmo título (Carlos, Alves, Pádua, 2017) organizado pelo Grupo de Estudos de Geografia Urbana Crítica Radical (Gesp), coordenado pela professora Ana Fani Alessandri Carlos. O segundo momento é uma mesa-redonda no Instituto de Estudos Avançados (IEA-USP) em junho de 2018 com o título Henri Lefebvre e a Utopia do Direito à Cidade. 
econômica. Esse posicionamento talvez tenha sido a causa de certo isolamento do grupo no debate crítico, mas também foi um dos elementos que constituiu a radicalidade com a qual ele pode ser associado.

\section{Considerações finais}

As duas principais fontes implicadas na trajetória de formação da geografia urbana crítica nascida no DG-USP convergiram no sentido de promover a centralidade da noção de produção do espaço. Já com a aproximação da teoria marxista, determinada forma de observar as relações entre o homem e a natureza pavimenta o caminho que coloca o trabalho como fundamento de uma geografia humana na qual o espaço deve aparecer eminentemente como produto social. Além de se haver tornado uma importante combatente na luta contra o descritivismo, o quantitativismo e o positivismo acrítico das vertentes tradicionais ou pragmáticas, a posição teórica daí derivada descortina o horizonte a partir do qual o diálogo com outros campos do conhecimento se poderá fazer mais livremente. A aproximação mais intensa aos textos de Henri Lefebvre também pontuará a extensão da crítica já incorporada ao trabalho dessa geografia nos campos da análise do cotidiano e da dimensão política. A radicalidade derivada dessa convergência marca a própria radicalidade da ruptura teórico-metodológica dessa geografia urbana com seus antecessores e muitos de seus contemporâneos. Assim, essa geografia urbana radical se caracteriza por ter desenvolvido um potencial crítico simultaneamente dirigido contra a realidade opressora e desigual desnudada pelo emprego de seus métodos e contra o próprio pensamento conformista e pseudocrítico que impõe limites à compreensão e ao combate dessa realidade.

\section{Referências}

ANDRADE, M. C. $\bigcirc$ pensamento geográfico e a realidade brasileira. Boletim Paulista de Geografia, São Paulo: AGB, n. 54, p. 5-28, 1977.

CARLOS, A. F. A. A condição espacial. São Paulo: Contexto, 2011.

CARLOS, A. F. A. A geografia brasileira, hoje: algumas reflexões. Terra Livre, São Paulo, v. 1, n. 18, p. 161-178, 2002.

CARLOS, A. F. A. Espaço tempo na vida cotidiana na metrópole. Tese (Livre-docência em Geografia Humana) - Faculdade de Filosofia, Letras e Ciências Humanas, Universidade de São Paulo, São Paulo, 2000.

CARLOS, A. F. A. O lugar no/do mundo. São Paulo: Hucitec, 1996.

CARLOS, A. F. A. A (re)produção do espaço urbano. Tese (Doutorado em Geografia Humana) - Faculdade de Filosofia, Letras e Ciências Humanas, Universidade de São Paulo, São Paulo, 1987.

CARLOS, A. F. A. Reflexões sobre o espaço geográfico. Dissertação (Mestrado em Geografia Humana) - Faculdade de Filosofia, Letras e Ciências Humanas, Universidade de São Paulo, São Paulo, 1979. 
CARLOS, A. F. A.; ALVES, G. A.; PÁDUA, R. F. (Org.). Justiça espacial e o direito à cidade. São Paulo: Contexto, 2017.

CARLOS, A. F. A.; LENCIONI, S. Alguns elementos para discussão do espaço geográfico como mercadoria. Borrador - Teoria e Método em Geografia, São Paulo: AGB, v. 1, p. 1-9, 1982.

DAMIANI, A. L. Introdução a elementos da obra de Henri Lefebvre e a geografia. Revista do Departamento de Geografia, São Paulo, v. 30, p. 254-283, 2012. Número especial.

DAMIANI, A. L. Urbanização crítica e produção do espaço. Cidades, Presidente Prudente, SP, v. 6, n. 10, p. 307-339, 2009.

DAMIANI, A. L. A propósito do espaço e do urbano: algumas hipóteses. Cidades, Presidente Prudente, SP, v. 1, n. 1, p. 79-96, 2004a.

DAMIANI, A. L. Urbanização crítica e situação geográfica a partir da metrópole de São Paulo. In: CARLOS, A. F. A.; OliVeIRA, A. U. (Org.). Geografias de São Paulo: representação e crise da metrópole. São Paulo: Contexto, 2004b. p. 19-58.

DAMIANI, A. L. As contradições do espaço: da lógica (formal) à (lógica) dialética, a propósito do espaço. In: DAMIANI, A. L.; CARLOS, A. F. A.; SEABRA, O. C. L. (Org.). O espaço no fim de século: a nova raridade. São Paulo: Contexto, 1999a. p. 48-61.

DAMIANI, A. L. A crise da cidade: os termos da urbanização. In: DAMIANI, A. L.; CARLOS, A. F. A.; SEABRA, O. C. L. (Org.). O espaço no fim de século: a nova raridade. São Paulo: Contexto, 1999b. p. 118-131.

DAMIANI, A. L.; CARLOS, A. F. A.; ANDRADE, M. M.; SEABRA, O. C. L.; OSEKI, J. H.; PINTAUDI, S. M. Présentation du programme d'études sur Henri Lefebvre au Labur (Laboratoire de Géographie Urbaine) - Brésil. La Somme et le Reste: Etudes Lefebvriennes - Réseau Mondial, Paris, n. 1, p. 6-8, 2002.

GONÇALVES, C. W. P. A geografia está em crise. Viva a geografia! Boletim Paulista de Geografia, São Paulo: AGB, n. 55, p. 5-29, 1978.

LEFEBVRE, H. A revolução urbana. Belo Horizonte: UFMG, 1999.

LEFEBVRE, H. O direito à cidade. São Paulo: Moraes, 1991.

MOREIRA, R. Assim se passaram dez anos: a renovação da geografia no Brasil no período 1978-1988. Revista GEOgraphia, Niterói: UFF, v. 2, n. 3, p. 27-49, 2000.

PINTO, A. V. Ciência e existência: problemas filosóficos da pesquisa científica. Rio de Janeiro: Paz e Terra, 1979.

PINTO, R. M. C. Uma hipótese para o capitalismo contemporâneo: análise a partir da geografia urbana lefebvriana da USP. Dissertação (Mestrado em Geografia Humana) - Faculdade de Filosofia, Letras e Ciências Humanas, Universidade de São Paulo, São Paulo, 2018. 
SEABRA, O. C. L. Territórios do uso: cotidiano e modo de vida. Cidades, Presidente Prudente, SP, v. 1, n. 2, p. 181-206, 2004.

SEABRA, O. C. L. Urbanização e fragmentação: cotidiano e vida de bairro na metamorfose da cidade em metrópole. Tese (Livre-docência em Geografia Humana) - Faculdade de Filosofia, Letras e Ciências Humanas, Universidade de São Paulo, São Paulo, 2003.

SEABRA, O. C. L. A insurreição do uso. In: MARTINSM, J. S. (Org.). Henri Lefebvre e o retorno à dialética. São Paulo: Hucitec, 1996. p. 71-86.

SEABRA, O. C. L. A muralha que cerca o mar: uma modalidade do uso do solo urbano. Dissertação (Mestrado em Geografia Humana) - Faculdade de Filosofia, Letras e Ciências Humanas, Universidade de São Paulo, São Paulo, 1979.

SILVA, A. C. A renovação geográfica no Brasil - 1976/1983 (As geografias crítica e radical em uma perspectiva teórica). Boletim Paulista de Geografia, São Paulo, n. 60, p. 73-140, 1984.

VERDI, E. F. Na busca do campo, o encontro com os fundamentos da cidade: Sandra Lencioni, um capítulo na história da geografia urbana crítica uspiana. Geousp - Espaço e Tempo, São Paulo, v. 20, n. 3, p. 481-497, 2016.

VERDI, E. F. Produção geográfica e ruptura crítica: a geografia uspiana entre $1964 \mathrm{e}$ 1985. Dissertação (Mestrado em Geografia Humana) - Faculdade de Filosofia, Letras e Ciências Humanas, Universidade de São Paulo, São Paulo, 2015. 